\title{
Overview of Engine Combustion Research at Sandia National Laboratories
}

\author{
Robert W. Carling \\ Sandia National Laboratories \\ Gurpreet Singh \\ Department of Energy
}


SAE routinely stocks printed papers for a period of three years following date of publication. Direct your orders to SAE Customer Sales and Satisfaction Department.

Quantity reprint rates can be obtained from the Customer Sales and Satisfaction Department.

To request permission to reprint a technical paper or permission to use copyrighted SAE publications in other works, contact the SAE Publications Group.

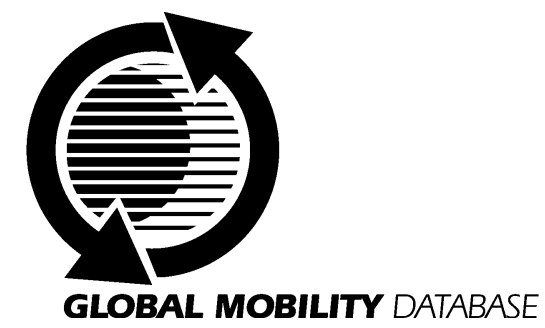

AII SAE papers, standards, and selected books are abstracted and indexed in the Global Mobility Database

\section{ISSN 0148-7191}

Positions and opinions advanced in this paper are those of the author(s) and not necessarily those of SAE. The author is solely responsible for the content of the paper. A process is available by which discussions will be printed with the paper if it is published in SAE Transactions. For permission to publish this paper in full or in part, contact the SAE Publications Group.

Persons wishing to submit papers to be considered for presentation or publication through SAE should send the manuscript or a 300 word abstract of a proposed manuscript to: Secretary, Engineering Meetings Board, SAE.

\section{Printed in USA}




\title{
Overview of Engine Combustion Research at Sandia National Laboratories
}

\author{
Robert W. Carling \\ Sandia National Laboratories \\ Gurpreet Singh \\ Department of Energy
}

Copyright @ 1999 Society of Automotive Engineers, Inc.

\begin{abstract}
The objectives of this paper are to describe the ongoing projects in diesel engine combustion research at Sandia National Laboratories' Combustion Research Facility and to detail recent experimental results. The approach we are employing is to assemble experimental hardware that mimic realistic engine geometries while enabling optical access. For example, we are using multi-cylinder engine heads or one-cylinder versions of production heads mated to one-cylinder engine blocks. Optical access is then obtained through a periscope in an exhaust valve, quartz windows in the piston crown, windows in spacer plates just below the head, or quartz cylinder liners. We have three diesel engine experiments supported by the Department of Energy, Office of Heavy Vehicle Technologies: a one-cylinder version of a Cummins heavy-duty engine, a diesel simulation facility, and a onecylinder Caterpillar engine to evaluate combustion of alternative diesel fuels.
\end{abstract}

\section{INTRODUCTION}

The engine combustion department at Sandia National Laboratories' Combustion Research Facility has had a close interaction with the United States engine manufacturers for nearly 20 years. Our original research involved the application of advanced, primarily laserbased, diagnostics to optically accessible single-cylinder engines. Compromises in engine geometry were made to accommodate optical accessibility; for example, using valves and spark plugs mounted in the side wall of the combustion chamber allowed the use of a window providing nearly full-bore, optical access to the cylinder. Over the past several years, advances in lasers, in computer speed and storage capacity, in electronics, and in detectors have enabled our researchers to consider more realistic geometries. Today, all of our single-cylinder engines employ production or prototypical engine heads. Optical access is accomplished via several means: extended (Bowditch) pistons, periscopes in an exhaust valve, quartz cylinder liners, or windowed spacers between the piston liner and head.

This paper is intended to describe the current facilities and projects and present recent results. It is divided into three sections focusing on each experiment funded via the Department of Energy, Office of Heavy Vehicle Technologies: a one-cylinder version of a Cummins heavy-duty engine, a diesel simulation facility, and a onecylinder Caterpillar engine to evaluate combustion of alternative diesel fuels. This paper draws from several recent publications and provides a current summary of our progress in understanding in-cylinder diesel combustion.

\section{SPECIFIC EXPERIMENTS}

Each section will discuss a specific experiment and recent results.

SANDIA/CUMMINS HEAVY-DUTY ENGINE - Recognizing the need for a greater understanding of the diesel combustion process, a considerable effort has been made in recent years to obtain detailed in-cylinder measurements. These studies have significantly improved our understanding of diesel combustion. This project is focused on learning where and when soot and NOx form in the cylinder of an operating, optically accessible engine.

Experimental hardware - The engine we are using is a one-cylinder version of a 4-stroke diesel engine based on a Cummins $\mathrm{N}$-series production engine. The $\mathrm{N}$-series engine is typical of heavy-duty diesel engines (class $7 \&$ 8), with a bore of $140 \mathrm{~mm}$ and a stroke of $152 \mathrm{~mm}$. These dimensions are retained in the optical-access engine, and a production Cummins $\mathrm{N}$-series cylinder head is used so that the production engine intake port geometry is also preserved. The design of this engine utilizes a classic extended piston with piston-crown window. This piston-crown window provides a full view of the 
combustion bowl. Figure 1 presents a schematic of the engine. A complete description of this engine may be found in Ref. [1].

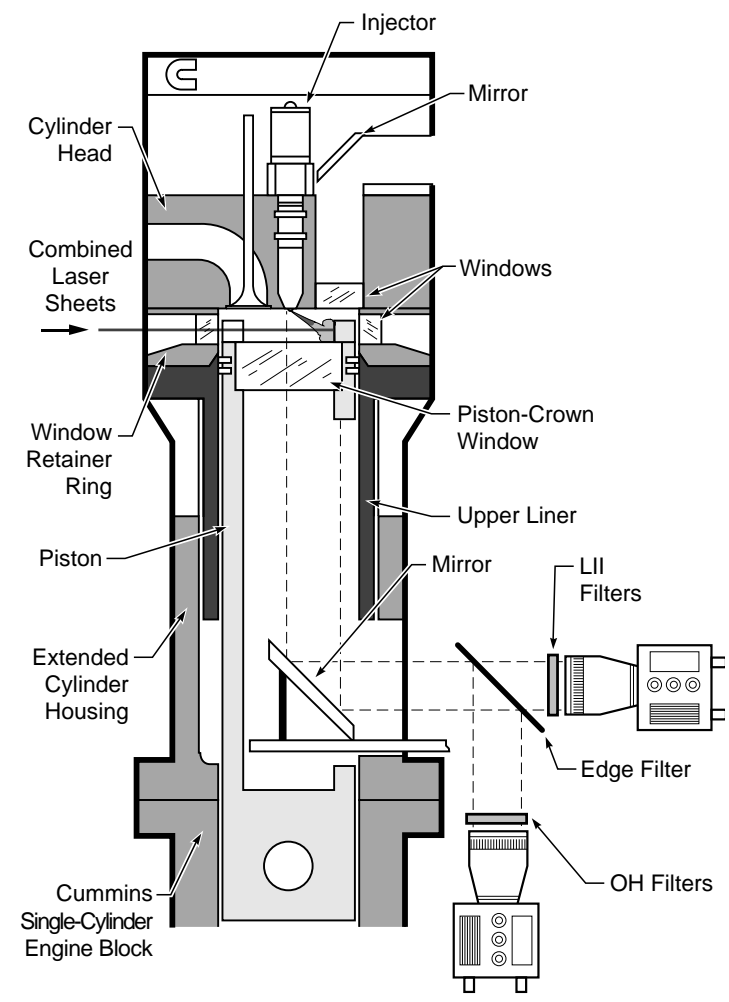

Figure 1. Schematic of optical-access diesel engine showing the orientation of the combined laser sheets and the location of the cameras.

Recent results - The understanding of diesel combustion and emissions formation has been considerably advanced in recent years by the application of advanced laser diagnostics [2]. For the most part, however, previous works have focused on the early and middle stages of diesel combustion, i.e., spray development, the starting combustion transient, and the developed, "quasisteady" portion of the combustion event. Investigations of the late stages of diesel combustion have been limited to high-speed visualization of the natural flame luminosity, gas sampling, and our recent laser-imaging study of NO formation that covered the entire combustion event [3]. As a result, little is known about the mechanisms whereby soot escapes combustion and becomes a tailpipe emission. The objective of the current work is to investigate late-combustion soot burnout in a firing diesel engine by simultaneously imaging the $\mathrm{OH}$-radical and soot distributions using planar laser-induced fluorescence (PLIF) and laser-induced incandescence (LII), respectively.

Measurements were made in an optically accessible direct-injection (DI) diesel engine of the heavy-duty size class, derived from a Cummins $\mathrm{N}$-series production engine. As shown in Fig. 1, windows in the piston crown and near the top of the cylinder wall provide orthogonal optical access for laser-sheet imaging. A dual-laser, dualcamera system was used to obtain the simultaneous "single-shot" images. The OH PLIF laser was tuned to a strong feature of the A-X, $(1,0)$ transition at $284.01 \mathrm{~nm}$ [4], and a frequency-doubled Nd:YAG laser (532 nm) was used to create the LII signal. Similar to our NO-PLIF study [3], the combined laser sheets entered the combustion chamber opposite the imaged area, and the fuel injector was fitted with a custom tip that had a "missing" jet opposite the imaged area so that the laser was not attenuated prior to entering the probe volume (see Fig. 1). Images were acquired through the pistoncrown window with the $\mathrm{OH}$ and LII signals being separated into the two intensified video cameras by means of an edge filter. Each camera was equipped with additional filters to isolate the appropriate signal $[5,6]$.

During the late stages of diesel combustion, $\mathrm{OH}$ radicals occur in the remaining diffusion flame zones and the hot combustion-product regions. Because $\mathrm{OH}$ occurs only in these regions, and because $\mathrm{OH}$-radical attack is considered to be the main mechanism for soot oxidation [5], the $\mathrm{OH}$ radical distribution is a particularly good marker of regions within the cylinder where soot oxidation can occur. Images of the soot distribution show where soot remains during the late stages of diesel combustion, and simultaneous images of the $\mathrm{OH}$ and soot show their relative locations, allowing the potential for oxidation of the remaining soot to be assessed.

Temporal sequences of simultaneous $\mathrm{OH}$ and soot images have been obtained during the late stages of diesel combustion for several laser-sheet elevations and various injection timings, engine speeds, and fuel loadings. Two of these images are shown in Fig. 2. In order to show the spatial relationship between the distributions, the $\mathrm{OH}$ and soot images have been superimposed and are shown in shades of green and red, respectively, with the overlap between the distributions being shown in yellow.

The image in Fig. $2 a$ is typical of the early part of the burnout period. The remains of the leading portion of the combusting fuel jet have spread out along the combustion chamber wall and appear as a large, intact region of soot (and unconsumed fuel) at the right of the image. The thin $\mathrm{OH}$ zone at the left-hand edge of the sooty region indicates the presence of a diffusion flame at the periphery of the soot/fuel region. As the burnout progresses (Fig. 2b), some of the soot and fuel are consumed, and motion due to the momentum remaining from fuel injection tends to break this sooty region into two or more smaller pockets of soot, which may or may not be connected out of the image plane. By this time, $\mathrm{OH}$ is typically present in broader regions adjacent to the sooting regions as well as around the periphery of these regions, as shown in Fig. 2b. This suggests that these regions are still surrounded by diffusion flames where soot and fuel are oxidizing, but that $\mathrm{OH}$ also persists for some time in the hot post-combustion gases. 


\section{Green: OH (LIF) Red: Soot (LII)}

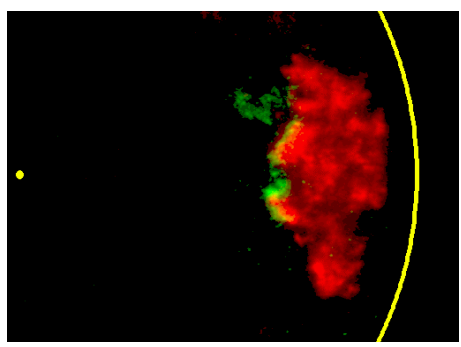

a

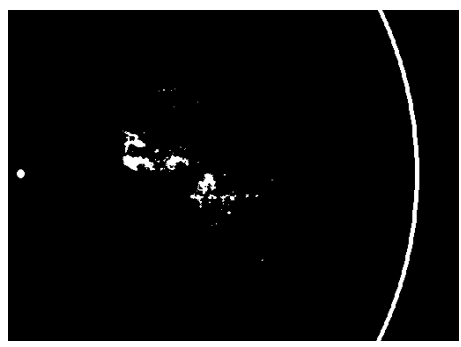

b

Figure 2. Simultaneous OH-PLIF and LII-soot images at two times during the late-combustion soot burnout. The $\mathrm{OH}$ and soot images are superimposed and shown as shades green and red, respectively, with the overlap regions shown in yellow. The small yellow dot at the left shows the location of the injector, and the yellow curve at the right shows the location of the edge of the combustion bowl when the piston is near TDC, as shown in Fig. 1.

At later times, the burnout follows different paths depending on engine operating conditions. In some cases, the remaining soot pockets gradually disappear while $\mathrm{OH}$ persists somewhat longer, indicating complete soot burnout in the bulk gases. However, in other cases, the rate of soot oxidation appears to slow as the $\mathrm{OH}$ signal becomes weaker and less widespread, while pockets of soot persist well after exhaust valve opening. In some of these cases, combustion reactions end (or at least slow to the point that no $\mathrm{OH}$ signal is evident) with only pockets of soot remaining. Soot pockets such as these almost certainly become tail-pipe emissions.

\section{DIESEL COMBUSTION SIMULATION FACILITY - Over} the past several years, diesel engine manufacturers have boosted in-cylinder gas densities to maintain efficiency and reduce emissions. It is likely that there will be a continued push to higher pressures as emission regulations become more stringent. However, little is known about the effects of gas densities higher than those in current technology diesel engines on injection, combustion and emissions processes. This project provides data on a wide range of diesel conditions.
Experimental hardware - The facility employs a constant volume vessel, shown in Fig. 3, which is used to generate simulated diesel conditions at the time of fuel injection. Details of the experimental hardware can be found in Ref. [7] but a brief description is provided here. A premixed, combustible gas mixture is introduced into the vessel and ignited with a spark plug. When the conditions of interest (pressure and temperature) are achieved, the diesel fuel is injected into the vessel. A typical pressure history of the diesel simulation process is shown in Fig. 4.

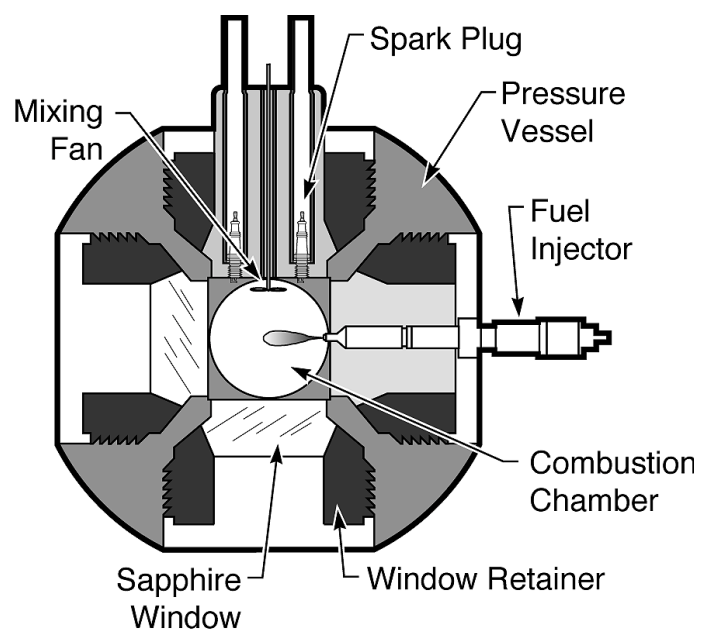

Figure 3. Schematic of diesel simulation vessel.

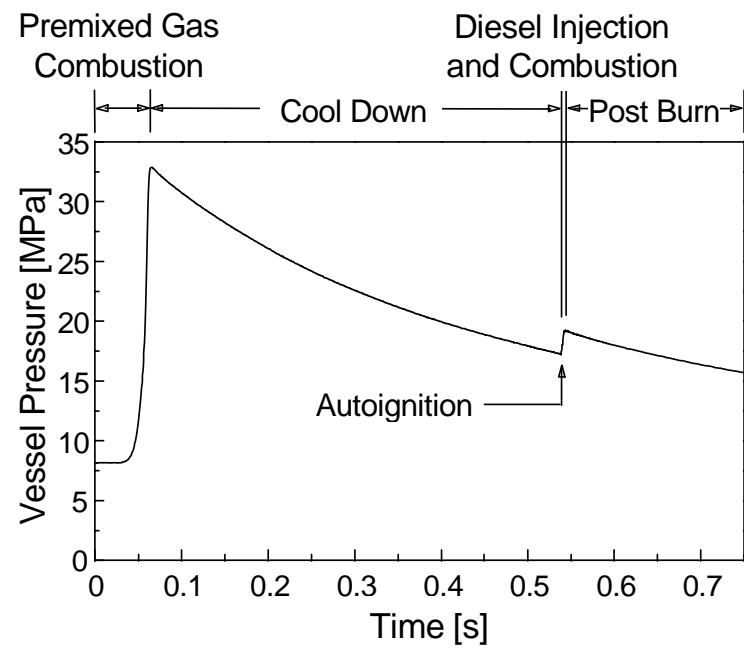

Figure 4. An example pressure history of the diesel simulation process for a combusting condition.

Recent results - Penetration of fuel sprays in a directinjection (DI) diesel engine promotes fuel-air mixing, but impingement and collection of liquid-phase fuel on incylinder surfaces can lead to greater emissions. As a result, understanding how various parameters affect the penetration of liquid-phase fuel and which processes control fuel vaporization in a diesel spray are important, both to the engine designer and to those developing multi-dimensional computational models for use as engine design tools. 
Recent experimental research on liquid-phase fuel penetration and vaporization in sprays has suggested that vaporization in a DI diesel spray approaches a limit controlled by turbulent mixing processes in the spray [7]. Using the concept of mixing limited vaporization, a scaling law has been developed for the maximum penetration distance of liquid-phase fuel in a diesel spray (defined as the liquid length). This scaling law was developed by applying conservation of mass, momentum, and energy to a simplified model of a diesel spray.

The scaling law accounts for the effects of injector, fuel, and in-cylinder conditions on liquid length. Comparison of the scaling law to measured data shows that the scaling law reproduces the trends observed in the experimental data with respect to all parameters considered. These parameters included: orifice diameter, orifice flow coefficients, injection pressure, fuel properties, incylinder gas temperature, density, and pressure.

Figures 5 and 6 present a comparison of the scaling law with measured data. These figures show the effects of ambient gas temperature and density on liquid length for two single component fuels, cetane and heptamethylnonane. The gray region in the figure is the range of liquid lengths expected for each fuel for typical lightand heavy-duty DI diesel engine conditions.

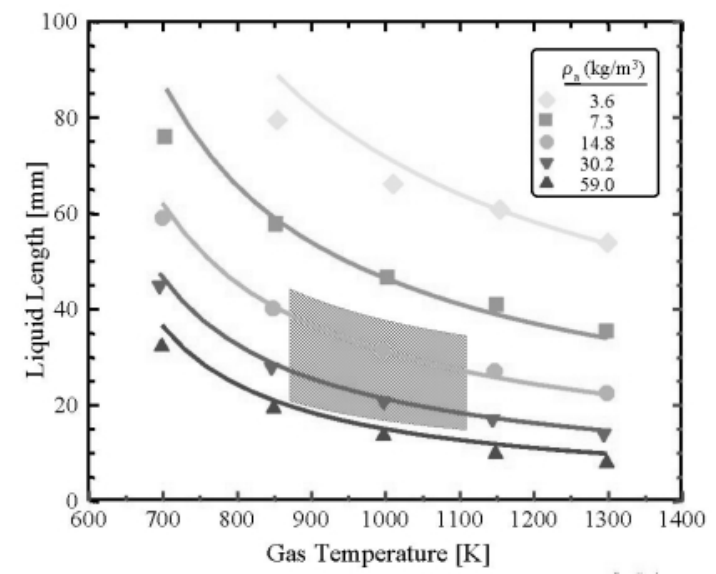

Figure 5. Cetane liquid length as a function of gas temperature for five gas densities $\left(r_{a}\right)$. The symbols are measured data and the curves are given by the scaling law. The orifice pressure drop, the orifice diameter, and the fuel temperature were $136 \mathrm{Mpa}, 246 \mathrm{~mm}$, and $438 \mathrm{~K}$, respectively. The light gray region in the figure represents the range of liquid lengths expected in light and heavy-duty DI diesels.

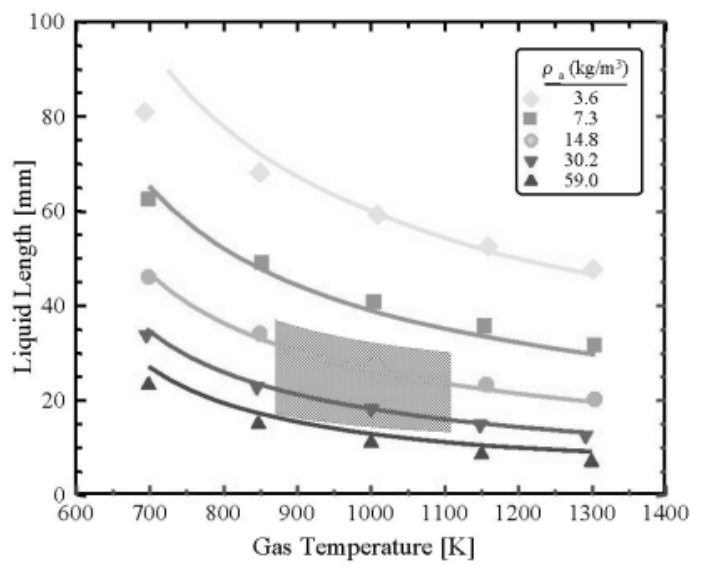

Figure 6. Heptamethylnonane liquid length as a function of gas temperature for five gas densities. See Fig. 5 for details.

The close agreement noted between the scaling law and measured liquid length data supports the concept that vaporization in sprays from DI diesel injectors is limited by mixing processes in the spray. An implication of mixing limited vaporization is that the processes of atomization and the ensuing interphase transport of mass and energy at droplet surfaces are not limiting steps with respect to fuel vaporization in DI diesel sprays. This further implies that better atomization (i.e., smaller droplets) alone will not promote increased fuel vaporization. Parameters such as injection pressure and orifice diameter affect fuel vaporization through their effect on mixing processes, not through their effect on droplet size (i.e., atomization).

An additional observation drawn from the scaling law is that fuels with properties comparable to typical diesel fuel do not reach supercritical temperatures before they are completely vaporized in DI diesels.

The scaling law provides a fundamental baseline on liquid fuel penetration and vaporization in diesel sprays that can be compared with the vaporization aspects of the multi-dimensional diesel spray models under development. The scaling law can also provide design guidance on the expected maximum extent of liquidphase fuel penetration in diesel engines; in particular for the small-bore DI diesels currently being developed for automotive applications.

\section{SANDIA ALTERNATIVE FUELS RESEARCH}

The fuel for heavy-duty transportation is primarily petroleum-based (99 percent), and it is projected that by the year 2010, heavy-duty transportation alone will consume an amount equal to all the domestic petroleum production. As a result, development of advanced, highefficiency diesel engines that operate on alternative fuels or in a flexible-fuel mode, while meeting stringent new emissions regulations, will have significant payoff for 
efforts to reduce petroleum imports and improve air quality. Our work in this area seeks to understand the incylinder combustion performance of a heavy-duty diesel engine operating on a variety of alternative liquid fuels.

\section{EXPERIMENTAL HARDWARE - The}

experimental facility for this project is similar to the one-cylinder Cummins engine described above but built on a onecylinder, Caterpillar 1.7 liter engine. The engine is shown in Fig. 7 and has recently been completed with in-cylinder combustion measurements currently underway. Optical accessibility is similar to that in the Cummins engine described above.

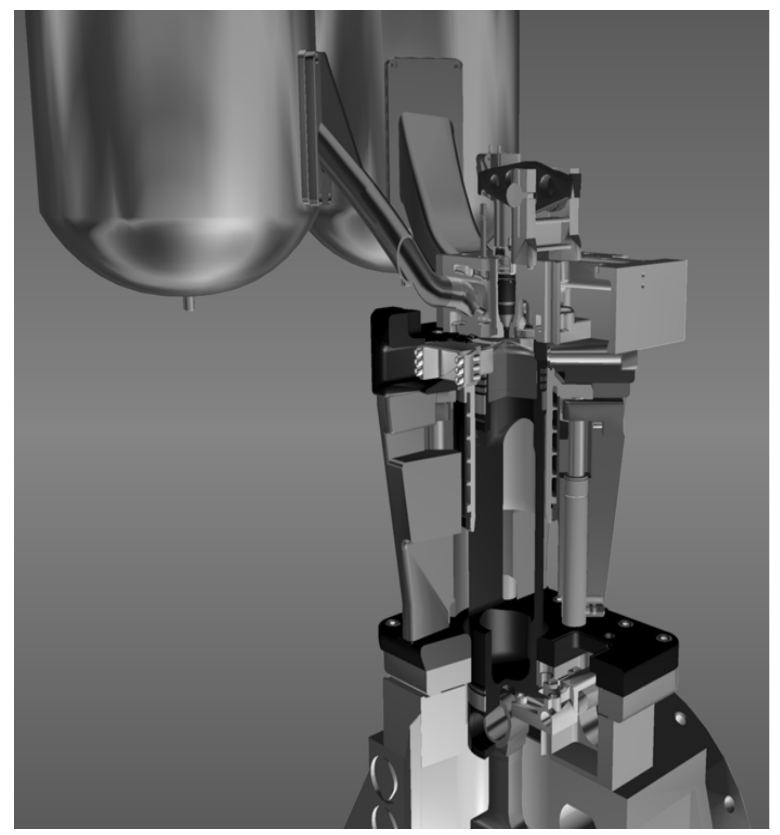

Figure 7. Cross section of alternative fuels engine built on a Caterpillar 1.7 liter, one-cylinder engine.

RECENT RESULTS - While the hardware for optical accessibility was being designed, fabricated, and implemented in the engine, experiments on liquid alternative fuels were conducted in the diesel simulation vessel. The goal of the study in the simulation vessel was to measure and correlate the liquid lengths of fuels with wide physical property variations. Liquid-phase fuel penetration into in-cylinder gases is an important parameter in compression-ignition engine design. Penetration of the fuel is needed to promote fuel-air mixing, but over-penetration of the liquid phase and impingement on the bowl wall can lead to higher emissions. This maximum liquid-phase penetration, or "liquid length," is a function of fuel properties, in-cylinder conditions, and injection characteristics.

Liquid lengths were measured for the following nine fuels: Fischer-Tropsch diesel (FTD); biodiesel (B100); methanol (M100); a non-oxygenated, hydrocarbon gasoline (HCG); an oxygenated, reformulated gasoline (RFG); a blend of 85 percent methanol and 15 percent gasoline(M85);nhexadecane(NHD); heptamethylnonane (HMN); and Phillips \#2 reference diesel fuel (DF2) [Ref to 1999-01-
0519]. The fuels were injected into a large range of incylinder temperature ( 700 to $1300 \mathrm{~K}$ ) and density (3.6 to $\left.59 \mathrm{~kg} / \mathrm{m}^{3}\right)$ conditions, at an injection pressure (140 MPa) that is characteristic of that provided by current highpressure injection equipment.

Previous studies have demonstrated a linear correlation between liquid length and fuel volatility, as characterized by $T_{90}$, the fuel's $90 \%$ boiling point $[7,8]$. Figure 8 shows the data duplicated from these two studies and recent data taken on the alternative fuels mentioned above. It is evident from the figure that a $T_{90}$ scaling is valid for some of the alternative fuels, however, it cannot explain all the measured trends. For example, the measured liquid lengths of the methanol-containing fuels are at least five times longer than those predicted by a $T_{90}$ scaling, and gasoline liquid lengths are $30-40 \%$ longer than predicted. A motivation for this work was to determine what other fuel properties affect liquid length and why.

Discrepancies between measurements and predictions of the type shown in Fig. 8, along with the need for physical understanding of the vaporization of the liquid core in a diesel spray, led Siebers [9] to develop a predictive liquid-length scaling law for single-component fuels. However, the scaling law requires detailed statedependent property data which are only available for single-component fuels. To handle multi-component fuels, an engineering correlation was developed using thermodynamic properties to predict liquid lengths for fuels of arbitrary composition.

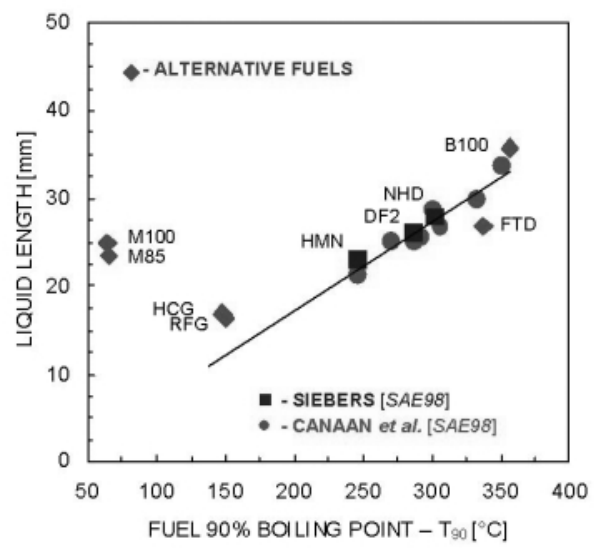

Figure 8. A linear scaling of liquid length with fuel volatility (i.e., boiling point) is not accurate for some alternative fuels, especially those containing methanol. All results have been scaled to $16.6 \mathrm{~kg} / \mathrm{m}^{3}, 992 \mathrm{~K}$, and an orifice diameter of $0.194 \mathrm{~mm}$. Open circles represent various diesel-like fuels examined by Canaan et al.

A complete description of the engineering correlation used to relate liquid length to easily measured or estimated fuel-blend properties can be found elsewhere [10]. In brief, a dimensionless parameter, referred to as 
the "specific energy ratio," has been introduced. The specific energy ratio is defined as the energy required to vaporize a unit mass of fuel divided by the energy available per unit mass of in-cylinder gas. Correlation constants were then determined using experimental data for three single-component fuels: heptamethylnonane, nital-hexadecane, and methanol. The engineering correlation accounts for variations in boiling point temperature, specific heat, latent heat of vaporization, fuel density, and gas temperature and density, but not injector characteristics other than orifice diameter.

This correlation has been applied to all the alternative fuels mentioned above and predicts liquid lengths to within $+12 \%$ over the entire range of temperature and density conditions studied. To illustrate the effectiveness of the correlation in this paper, the measured and correlated results on reformulated gasoline, a multicomponent fuel, are shown in Fig. 9.

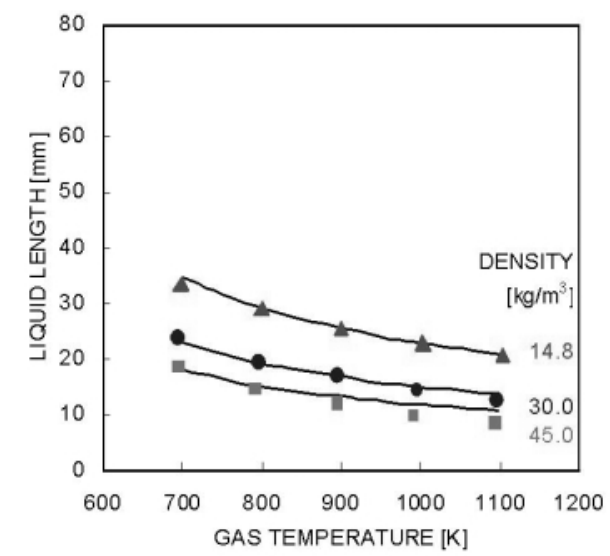

Figure 9. Measured reformulated gasoline (RFG) liquid lengths (symbols) and correlation results (lines) vs. temperature for four different densities. Correlation results used a mixture of all species comprising over $1 \%$ of the fuel (by mass) to estimate mixture properties. Fuel composition was determined by GC analysis. Initial fuel temperature was $367 \mathrm{~K}$.

\section{ACKNOWLEDGMENTS}

This work was performed at the Combustion Research Faility, Sandia National Laboratories, Livermore, CA. Funding support was provided by the U.S. Department of Energy, Office of Heavy Vehicle Technologies. The authors would also like to express their appreciation to the principal investigators of the projects described above: John Dec (Sandia/Cummins engine), Dennis Siebers (diesel simulation vessel), and Chuck Mueller (alternative fuels).

\section{REFERENCES}

1. Espey, C. and Dec, J. E., "Diesel Engine Combustion Studies in a Newly Designed Optical-Access Engine Using High-Speed Visualization and 2-D Laser Imaging," SAE Transactions, Vol. 102, Secl 4, pp. 703-723, paper no. 930971, 1993.

2. Dec, J. E., "A Conceptual Model of D.I. Diesel Combustion Based on Laser-Sheet Imaging," SAE paper 970873, 1997.

3. Dec, J. E. and Canaan, R. E., "PLIF Imaging of NO Formation in a DI Diesel Engine," SAE paper 980147, 1998.

4. Dieke, G. H. and Crosswhite, H. M., "The Ultraviolet Bands of $\mathrm{OH}$ Fundamental Data," J. Quant. Spectrosc. Radiat. Transfer, Vol. 2, pp. 97-199, 1962.

5. Dec, J. E. and Coy, E. B., "OH Radical Imaging in a DI Diesel Engine and the Structure of the Early Diffusion Flame," SAE Transactions, Vol. 105, Sec. 3, pp. 1127-1148, paper no. 960831, 1996.

6. Dec, J. E. and Espey, C., "Ignition and Early Soot Formation in a D.I. Diesel Engine Using Multiple 2-D Imaging Diagnostics," SAE Transactions, Vol. 104, Sec. 3, pp. 853-875, paper no. 950456, 1995.

7. Siebers, D.L., "Liquid-Phase Fuel Penetration in Diesel Sprays," SAE paper 980809, 1998.

8. Canaan, R.E., Dec, J.E., and Green, R.M., "The influence of Fuel Volatility on the Liquid-Phase Fuel Penetration in a Heavy-Duty D.I. Diesel Engine," $S A E$ paper 980510, 1998.

9. Siebers, D.L., "Scaling Liquid-Phase Fuel Penetration in Diesel Sprays Based on Mixing-Limited Vaporization," SAE paper 1999-01-0528, 1999.

10. Higgins, B.S., Mueller, C.J. and Siebers, D.L., "Measure-ments of Fuel Effects on Liquid-Phase Penetration in DI Sprays," SAE paper 1999-01-0519, 1999. 